\title{
The Cost and Effect of Gendering in the Family
}

\author{
Callie R. Davidson, Keisha E. Payne, Saskia Maltz, Jerome Rabow \\ University of California, Los Angeles, USA \\ Email: jrabow@soc.ucla.edu
}

Received 27 June 2015; accepted 18 September 2015; published 21 September 2015

Copyright (C) 2015 by authors and Scientific Research Publishing Inc.

This work is licensed under the Creative Commons Attribution International License (CC BY). http://creativecommons.org/licenses/by/4.0/

(c) (i) Open Access

\begin{abstract}
This paper examines theoretical and empirical research on how families teach children about gender, gender relations, and gender roles. This research is supplemented with students' personal childhood vignettes from two upper division classes, at two public universities. A final section examines shifts in traditional family structure that affect child rearing practices and the students' efforts to resist the inequalities they faced. This structural shift and micro practices both lead to less oppression and more equality in the modern family.
\end{abstract}

\section{Keywords}

Sexism, Gender Stereotypes, Gender Roles, Family Influence on Gender, Socialization, Single Parent, Gay Parenting

\section{Introduction}

Through infancy, the family constitutes the most powerful foundation for children's conceptions of gender and their own gender identity. This paper addresses the most immediate influences on acquiring gender perspectives - that of parents and other caregivers, as well as extended family members (Lauer, R. H., \& Lauer, J. C., 2011; Santrock, 2013; Kaplan, 1991). We take family to include biological and non-biological persons who play a primary role in influencing a child's conception of what it is to be boy or girl, man or woman. Familial influences vary in strength, mode, content, birth order and structure (Carballo, Garcia-Nieto, Alvarez-Garcia, Caro-Canizares, Lopez-Castroman, Munoz-Lorenzo, de Leon-Martinez, \& Baca-Garcia, 2013; Marks, Bun Lam, \& McHale, 2009).

\section{Methods}

Our literature review on family influences covered the years 1973 through 2015 from all social sciences. As this

How to cite this paper: Davidson, C. R., Payne, K. E., Maltz, S., \& Rabow, J. (2015). The Cost and Effect of Gendering in the Family. Sociology Mind, 5, 227-238. http://dx.doi.org/10.4236/sm.2015.54020 
research is quite extensive, we were selective using materials that could be supplemented with personal accounts of students. These vignettes come from two upper division classes at two different public universities. Students in these classes as part of their regular assignment were asked to evaluate how the readings on gender applied to themselves. They also provided web-posts about these reading and class experiences, which were not monitored by the professor or class facilitators. When the class was over, we contacted students about using their written papers and webposts. All vignettes in this paper have been approved by the students.

\section{Sample}

The two classes had 65 students and we have used 38 vignettes from 30 students. No claims are made for the representation of the sample to the university wide population. The great majority of the students were social science majors.

\section{Findings}

\subsection{Earliest Influences}

"Is it a boy or a girl?" This is a question expecting parents will hear countless times from friends, family, and coworkers after the announcement of a pregnancy.

"From the moment my mother gave birth to me and I had a vagina instead of a penis, everyone labeled me as a female. From that day forward, my mother, grandmother, father and anyone else who crossed path with me referred to me as Britny, a female baby, a girl, a young lady and a woman. I could also remember my mother always referring to me as 'little girl' so I knew I was a female. She would always dress me up in bright pink dresses and Cinderella panties and she would put berets in my hair so that my beautiful long hair would just swing side to side. As a female, wearing a frilly laced dress with nicely combed long hair and with added colorful berets is exactly what my grandmother loved to see."

"Research demonstrates that male or female is usually the first category that people sort self and other into in social relational contexts" (Ridgeway \& Correll, 2004: 514). The sex of an expecting parents new baby will shape and define the characteristic nature of the parent-child relationship from birth. Most expecting parents consciously consider the gender of their children as they prepare their home for their newborn. Parents choose clothing, toys, and a room décor that "fits" with acceptable gendered expectations-girls get pink rooms with dolls, while boys get blue rooms with trucks (Kane, 2006: 151).

A young woman describes the different rooms she and her brother had.

"When I was a baby my mother was pretty traditional in following what society says is for baby girls and what is for baby boys. My room was decorated with all pink and purple decorations from the crib, to the paint on the walls, to all the clothes and accessories. But when my little brother came along, his room was all blue with animals printed on his bedding and carpets. This went along with the toys that my brother and I had played with or received from family members. I had baby dolls, Barbie dolls, kitchen sets with little dishes and, pots and pans. Sometimes I wanted to have some things that my brother played with such as his race car toys or his action figures. When I was a little older, probably 12, I realized that my parents never got us gender-neutral toys. They were always typically gendered toys."

The preverbal infant picks up on parental approval or disapproval toward certain play activities based upon "communication through intonation patterns, smiles, and frowns [which] are highly salient events that direct infants' behavior when their verbal skills are limited." (Bandura \& Bussey, 1999: 28).

\subsection{Toys and Play}

Between the ages of three and five, children establish deeply entrenched beliefs about gender. Children as young as three can identify "acceptable" (gender typical) versus "unacceptable" (gender atypical) toys when asked to predict their parents' reactions to their playing with those toys (Freeman, 2007).

Toys are not just a backdrop in a child's life. Gendered playthings like baby dolls, domestic toys, and Barbies versus trucks, building toys, and action figures are in and of themselves tools to actively build a framework establishing what girls and boys are and what they should do. In the following, a young man describes his fascination with cars and drums. His older sister reinforces the parental support that he must have received for his toy preferences. 
"I remember having a distinct fascination to cars and the drums as a kid. I had Hot Wheels everywhere, and anything I could hit quickly became a part of drum set. I had Nerf guns, basketballs, and video games like other boys had at my disposal as well. I never remember my parents telling me that my toys were toys for boys but I do remember my older sister having Babies [and] I wasn't allowed to play with them because according to her they were for girls."

Play prepares children for the gender role they will be expected to take on as adults. A woman describes playing with her Barbie dolls growing up while never feeling she wanted to look like them:

"I always had Barbie's when I was young and I remember thinking 'I' $m$ nothing like Barbie' my hair color and skin tone, everything was different from her and while I enjoyed playing with them, there was never a desire to change myself to be like them. However I can easily see how for many children Barbie was a symbol of the epitome of what a woman should be."

Once this gendered stage is set, parents, siblings, and other relatives reinforce boundaries by encouraging or discouraging their children from certain types of play or by providing strictly gendered avenues for play through the toys parents are willing to provide their children.

In this way awareness of adult sex role differences greatly impact play. By the age of two (Weinraub Clemens, Sockloff, Ethridge, Gracely, \& Myers, 1984) and a two and a half, children generalize gender stereotypes to a variety of activities, objects, and occupations (Fagot, Leinbach, \& OBoyle, 1992; Cowan \& Hoffman, 1986). For example, boys and girls recognize that a fire hat and a hammer are masculine objects, while a broom and an iron are female feminine, these are specific objects that accord with gender stereotypical preserves. Children can also infer and make associations to gender stereotypes as when they considered "a bear and an angry face (male) and a heart and a butterfly (female)" (Fagot, Leinbach, \& O'Boyle, 1992: 226). The research on gender labeling, stereotyping and sex-typed behavior, confirm that parents are key influences in these early expressions of gender.

"Generally, [...] girls received the gender-traditional toys they requested but did not receive the gender-nontraditional toys for which they asked" (Etaugh \& Liss, 1992: 136-137). Though the young woman who described the sex-typed rooms her parents made for her and her brother does not describe any attempts to play with her brother's toys, many children experience parental disapproval when selecting a toy that is not classified as gender appropriate. A young man recalls his experience:

"One of my first experiences with gender was being shamed by my mother when I got caught playing with a cat-woman action figure in the living room. Mom called it a doll and told me it wasn't a boy's toy. I felt embarrassed and put away that toy, which from then on played the role of damsel-in-distress rather than the heroine during playtime. She was very encouraging of sports and other masculine activities and I belonged to many different sport teams and academies throughout my childhood. She saw sports as the most apt way for me to show aggression and competitiveness; both of which are labeled as masculine traits. Another way she helped shape my gender was by being very authoritative and resorted to great physical and psychological punishment when I wasn't acting according to her expectations."

That parental approval or disapproval shape a child's outlook on play and games is evident in the following young woman's experience with her mother:

"I was pushed towards a certain behavior was when I was a kid around like age five or so when my mom did not let me play with my cousin and his friends. I lived with my cousins for a long while, so when his friends came over, they stayed in our house. He's about three years older than me, but when you're a kid it doesn't make that much difference when it comes to play time. Now, I don't even know if they would have let me join in at that particular time (but they usually did let me play if I wanted to), but the thought of rejection didn't deter me from asking. I wanted to go play video games with them because games are fun and there is only so many times I can play board games by myself. I didn't care that I would be the only girl there because all I saw were other people to play with. Oh, but my mom got pretty angry when I walked with them because she said that I was a girl, and girls are supposed to play with other girls with dolls and such and not video games with a bunch of boys."

By the age of 5, children have a rigid set of beliefs about gender which they apply to themselves, employ in their play with peers, and with others (Martin \& Ruble, 2004).

"At the age of four or five, I remember playing games that had to deal with house role usually taken on by women in society. I can recall being the little girl who was usually found in a kitchen replica toy set making pretend food and serving them on small dishes and walking them over to the table where usually a male was sitting ready to receive their meal. Sometimes I would even take on the role of a mother and carry around with me 
a baby doll, while cooking and delivering the food to the table where a boy usually sat.

\subsection{Familial Organization}

The traditional familial organization-in which the father serves as the breadwinner while the mother takes care of domestic duties-sets an example for children about how labor should be divided in the home. Fulcher, Sutfin, and Patterson's (2008) study of lesbian and heterosexual parents found that parental sexual orientation was less influential than attitudinal and behavioral. This suggests that family behaviors are often confused with the concept of family structures. The two should be examined independently to see how each impacts gender development in children and future orientations.

In the following a young woman describes how all family members reinforced a traditional division of labor.

"Growing up in my home there was women's work and men's work. Women took care of men, namely my dad, my brothers and I. My Christian family members reinforced these roles. When they talked about marriage and relationships, it was assumed that the man would make the money. One of my aunts even discussed how God made woman from a man's rib, not his head, so a woman could never be the leader of a man."

"My grandmother, a woman who I look up to and appreciate deeply, echoed these comments. She emphasized how my grandfather worked hard, got a good job, and took care of the family. His family, mind you, consisted of a wife, many daughters, and only one son. My dad never spoke badly about my mom, and he never put women down, but I don't think it occurred to him to encourage my mom to do things like get a better job or go to school because he was the man, and men take care of their families."

Traditional families are not without conflict. A twenty year old college student describes her father's irritation when a family member breaks from a traditional role during a family gathering:

"A couple of week ago we had Easter dinner at my house. My entire mom's side of the family came over and it was a lot of fun and all that. However, at the end of dinner, the same thing ALWAYS happens. All the men go sit and talk outside and ALL the women start cleaning up and washing dishes. It's irritating me so dang much, but I can't say anything about it. Only one of the men stayed behind to help out and my dad kept telling me that its embarrassing having him helping us and that I should be doing it. I asked our friend to please go outside and enjoy the conversation, but he said no. He wanted to help us. I was so happy with that."

Traditional family environments stress the authority of the man over his household and that women and children are expected to obey and respect the father figure under any and all circumstances.

"I was also taught mostly by both parents, but mostly by my dad, that when talking to a man, women are supposed to be modest in a way, showing the man that he is being respected, he was in a [position] of authority. My mom and dad's relationship was a great example of this. My dad would be mad at [my mom] calling her hurtful names and cursing, but once she would try to stand up for herself, it would make him even more mad that she just tried to be above him, as if she forgot her place in the relationship."

A student describes the efforts of her mother to break from a traditional family role and it's consequences.

"One time I was at home and I heard my mother and stepfather [...] arguing and fighting. Later I asked my mom what happened and she told me that they were fighting because she is tired of staying at home, taking care of my younger sisters and wants to go out once in a while during the week. My mom said that she was asking my step dad to hire a nanny for one or two days a week for a couple of hours so that she can go out. She continued to explain to me that men in the [...] culture always think they are right and even when they know that they are wrong, they will never admit it and continue to place blame on women."

A more detailed vignette about the traditional division of labor is described by a young man.

"My poor mother slaving away in a hot kitchen after been working all day, the sweat dripping from her brow, the stress building up in her shoulders, she was always tired, its natural the body can only take so much. And then to look over, and see my father laid flat of the couch, air conditioner right by his face, with a cold iced water, asking when diner is ready because he is hungry. You could see all the stress of his day leaving his body, as he relaxes watching television, and my mother is well into her second shift, the household shift. This is what it was growing up, the mere fact that women took care of the household, and did everything for the males in the house."

With no other model than his family, this man, although taught later to respect his mother and all women, was taught that to be masculine is to rest after work and relax with cool water. As a man, his own father had no "household shift". Instead, the stress of cooking and taking care of the household was delegated to the women of 
the home. These early lessons teach young boys where power lies in the home and how to reconstruct that model later in life.

The traditional family may instill gender typical behavior through members other than parents. In the following, a young woman receives a lecture from her grandmother on appropriate behavior for her as well as her boyfriend. Though the student recognizes that times have changed, she feels guilty about not being comfortable in the traditional role.

"We had a small gathering to celebrate my sister's 5th birthday. My grandmother overheard a conversation that I was having with my previous boyfriend and she walked up to us, very serious. She told me that my job as a woman is to do everything that he wants. If he wants me to cook, clean, or provide something for him, I must do it. That there are not questions about it. She then turned around and told him, 'Listen, if she does not listen to you, hit her. She needs to understand her duties around you.' I looked at my grandmother in shock to what she had just said. I told her that I was not going to let [any] man hit me because of a woman's role nor for any other reason. So, if he ever wanted to do that, he would be walking straight into his home and would never see me again. I told her that we are in a different time and that he has hands to do the job. Although, I did start to notice that I was pushed to serve him food, pick up his plate, wash after him, and sometimes bring him what ever he wanted as we were around his or my family. When I was told by mom or his mom to do that for him, they would make me feel as if I was a bad person and was not responsible enough in my woman role."

\subsection{Dress, Clothing and Appearance}

In addition to toys and play, parents often involve themselves in the dress, appearance, manners, chores, safety, and dating of their boys and girls.

Two women describe the treatment and advice they received about clothing and neatness.

"To be a good girl I had to dress a certain way, I had to act, listen to certain music and play a certain way. Towards the end of my third grade I no longer watched wrestling shows, I no longer chased my friends and played in the dirt. If I played outside I played picnic or Barbies with my neighbor on my front lawn, or we would ride our bikes to the park and back. I was really upset that I could no longer play in the dirt with the other girls who still played and chased each other in the dirt. I told them I couldn't play anymore. So we changed our way of playing, we still wrestled just not in the dirt. It was either in the grass or bark. Even as we wrestled on the grass or on the bark, I still had to be careful not to stain my clothes. It just wasn't as fun as before."

"My mom had to beg me to wear skirts. I always wore pants unless my mother made me which she often did [...] I had long hair, but it was slicked back in a ponytail with the excess braided from when I was three until fifth grade. I was very comfortable and found it difficult to remember that it was proper to sit correctly, to not let your underwear show, to not be able to play on the jungle gym at recess, and to not get dirty or mess up your hair. I was born a tom boy and all that girly stuff was going to get in my way."

Two vignettes about makeup are presented below. The first one indicating how "makeup" seems essential to a young woman's identity and the second describing a mother's reaction to her daughter's lack of makeup.

"My mother and almost every woman in my life have taught me that since I am a woman, I should always have a pretty face. I think that my mom and all my aunts, even my uncle, have been taught this and passed it down because this is what my grandma taught them. A woman should never be without lipstick or her hair done whether she leaves the house or not. My grandma was never without lipstick on and if she saw one of her daughters without it, she would tell them in Spanish, 'Mija, porque no te pintas los labios?' Whenever I don't get fully ready for the day, my mom tells me that I should at least put some lip gloss on."

"When I started high school, I began to wear makeup and my mom would even give me tips on how to apply it. At this point, I was not sure if I started to wear makeup because of my friend, my mom bought it for me, or because I felt I wanted to. I decided I would try to test what I can do with the stuff and see how I look afterwards. I was highly impressed [...] I noticed that it made me feel more womanly when I had it on. I was also getting from my mother that looked better with it on. I was definitely getting the external reinforcements necessary for me to keep applying the stuff to my face. Sometimes I would even feel like it was okay to go without the stuff but my mother would tell me that if I did not want to wear much make-up, I should at least have on mascara and blush, which were the essentials in her book of tips."

\subsection{Chores}

Chores are frequently gendered, with boys taking out the trash, doing maintenance, mowing or having no chores 
at all, while girls have more chores involving cleaning and kitchen duties (Etaugh \& Liss, 1992). One woman describes the introduction of chores early in her life as well as the different expectations set for her compared to her brother,

"As I got to the age of twelve, I began to act out the duties I would have Barbie pretend to do. I was not doing a lot, but I [had] already been picking up and cleaning my room/toys since I was under five. I was now learning how the dishes were done, how to wash my own clothes, pick up other items in the house, throw out the trash, among other things. I have been doing these things ever since. My brother, on the other hand, does not do too much around the house and is not really expected to. There are three of us out of the five family members living together and I am the one who performs the most domestic duties besides the cooking. I have bickered at my brother plenty to help out more than he does."

In the following a woman responds to her parents' expectations,

"As soon as I turned 14, my parents began comparing me to my sister by telling me I wasn't a good daughter like she was because at that age she already cleaned the house, had dinner ready every day, and even took care of me. Later when she got married she was always praised by both parents for having dinner made by the time her husband came home because catering to her husband made her a great wife. On the contrary, I was often told I would never be a good wife because I didn't even know how to cook and no man would want to marry me like that. I believed this to be true because I had witnessed my father become upset if my mother didn't have food ready when he asked for it, so I believed knowing how to cook and clean was a requirement to be someone's wife".

\subsection{Manners and Demeanor}

Discipline by parents frequently varies based on the gender of the child. McKee et al. (2007) found that "boys received more harsh verbal and harsh physical punishment than girls" (193). In the following two vignettes, "punishment-worthy" discipline is shown to be dependent on the gender of the child.

"I would get in trouble for burping out loud like my brothers. A few years ago when I burped, my mom told me that the next time I burp out loud there was going to be repercussions such as not having permission to go out with my friends or using my phone because that was not lady like. She never told that to my brother, not once. My brother felt that I shouldn't do that either. That it was acceptable for him to do because he was a guy and since I' $m$ a girl, it's basically 'forbidden' for me to even do it sometimes, even as a joke."

"My brother has a smart mouth. He never gets in trouble for what he says. My mother thinks it is so funny and she just laughs it off and my dad as well. The moment I call them out on it, they say he says it in such a funny way they cannot help but laugh and I let them know if I were to say something like that, I would get slapped in the mouth. My mother always denies it. I have been hit in the mouth before when I was much younger for something I said, so it really bothers me that I get treated differently because I am a female."

Demeanor is stressed when parents believe that being feminine means being modest, beautiful, passive, emotional, polite, nurturing, caring, "acting like a lady", and putting the needs of others before one's own goals (Esptein \& Ward, 2011: 110; Ember, 1973: 425).

"The earliest memory I have of being taught about my gender was around four years old, being told to act like a lady. That meant wearing dresses when needed, crossing my legs, no burping, and a certain way to talk. It's important to be sitting and walking the right way. If I slouched while sitting down or walking, my mom would correct me. Sometimes I know that she would tell me just to help me have good posture, but most of the time it was to not look lazy and to look like a lady, because having a correct posture made me more of a put together lady. If I was sitting down, I also had to make sure that my legs were a certain way. My mom would remind me to do so, but I also remember watching and reading about how a lady is supposed to sit. I know that the position of legs is helpful or sometimes needed when wearing a certain type of dress, but no matter if my dress was long or short, I would be told to 'put your legs together,' 'cross your legs' or 'cross your ankles."'

Demeanor also involves the conduct of male and female relations. Epstein and Ward (2011) report that women received messages on the importance of being "deferential to the men in their lives, to focus their energies on building romantic relationships, and to curb their sexual urges" (Epstein \& Ward: 118). Our college student confirms this.

"The women in my family were taught to be a little more submissive to the men, and my mom would always tell me to just keep quiet whenever my brother and I got into a fight. Because of the way I was taught growing 
up, I feel like a apart of this carried on with me as I got into relationships."

Boys do not escape from gendered expectations. They are expected to achieve masculine qualities of toughness, independence, ambition, and strength, emotional control, self-reliance and to strive for achievement and to initiate sexually (Epstein \& Ward: 118, Ember: 425).

In the following, a young man describes how his parents encourage him to "man up":

"[...] my father would be gone from the house for months at a time [because of his job] but he never failed to have a 'life' talk with me when he found it necessary. He would pull me into his room, sit me down and explain everything he thought a good man should be. He would tell me that I need to learn how to save my money so I could support a family of my own one day. All throughout my life he would constantly remind me of this principle. He would teach me how to be strong and decisive by making sure I spoke clearly and with confidence. He made sure to tell me not to ever let anyone take anything away from me. He taught me how to respect authority as long as they were within the confines of the law. He really stressed the importance of getting my education but he made sure that I knew that there is a difference between book smarts and street smarts. Another thing my father felt was very important to share with me was to learn how to be independent. He wanted me to learn how to cook, wash my clothes, clean my room, iron my clothes, how to tie a tie, how to wear a belt, how to dress for church and above all, taught me how not to look like a thug. [...] As I look back on these experiences, I realize my father has been a blessing to me but my mother was the one that really reinforced these ideals. My dad asked me one time if I was a man or a mouse when I was really young. My mom took it and ran with it. She would always ask if I was in a moment of weakness if I was a man or a mouse. This is how I got the notion that "boys don't cry."”

A mother strongly emphasizes to her son her ideals of what a man should be.

"[My mother $]$ did not sugar coat things, she did not take excuses, and there was very little room to express emotions of sadness or negativity. My mother wasn't very affectionate verbally or physically. There weren't a lot of hugs or saying 'I love you' in my household. There really wasn't much 'I am proud of you' either. Part of that I attribute to her mother not really doing very much of that with her, she always talked about how her mother was very critical with her so in a way she perpetuated that behavior with me. The other reason for her attitude, I believe, is that she was trying to teach me how to become a man. Men didn't dwell on emotional things or let them drag him down, that was stuff women did. Men didn't cry when they were hurt and surely not for more than a few minutes. Men didn't complain about things, they just did them and moved on and if anything upset you then you just sucked it up and moved on. My mom chastised me many times about being emotional. The phrase 'you better man up' was used so much that it became something of a mantra for her. My mother had very little patience for things she believed were unimportant or irrelevant so she did not have much for me behaving any way that she didn't want me to behave. She was giving me the groundwork for what she believed a man should be."

\subsection{Protective Behaviors}

Parents protect their children differently. One young man recalls his experience with his female siblings,

"I grew up with two sisters in my family and there were various privileges and responsibilities that came with that. One of the memories I have growing up was when my younger sister was born, I was between 4 - 5 years old and I recall my father telling me that I would have to protect her. At the time, I didn't know what that responsibility would entail, but what I figured it would be to always be there for her and to be a positive influence to her as an older brother as she grew up. It was a role that my father had instilled in me at an early age."

In an examination of parental monitoring of children, Kniveton found thatparents' accompanying girls on their way to school while letting boys go alone maintains "traditional sex-role stereotypes of protectiveness of girls" while "encouraging a greater degree of independence with boys" (Kniveton, 1996: 291). In the public realm, the spatial privileges granted to boys are typically more extensive and accompanied by more lenient rules than the spatial privileges of girls (Valentine, 1997: 39). In the following a young man notices the spatial privileges granted to him versus those of his female siblings,

"Both of my parents have been tremendously overprotective throughout all of our childhood. I was granted slightly more privileges and responsibilities as opposed to both my older and younger siblings. For example, when it came to me going over to a sleepover my parents were much more lenient. In fact, my sisters actually weren't able to sleep over at anyone's home until they were very close to them and only if my parents had known 
the parents well enough. Another example was that I could travel the Metro Bus at a young age if I wanted to but my sisters weren't allowed to ride the bus because my parents feared for their safety on the bus and also on the 1 mile walk from the bus to our home. We also had different curfews. At 16 years old I was able to be out until 1:00 am, whilst my sisters were expected to be home no later than 10:30 pm. If my sisters were a minute late, they were punished and not be allowed to go out."

In following vignette, a woman describes her mother's reaction when she breaks curfew as compared to her brother.

"As a female in my family, however, there was an early curfew anytime we went out and we always had a long talk from our parents if we broke curfew. My mom never stayed up to wait until my brothers came home from a night out, but if I went out my mother would constantly call me telling me to come home, and she would go as far as waiting for me by the door until 1 stepped inside."

\subsection{Dating}

Parental protectiveness of females becomes a very important issue with the blossoming of romantic interests during adolescence. Madsen (2008) found that parents set more rules around their daughters' dating activities than they did with their sons. Rules for daughters were also "more likely to contain supervision rules and to afford parents a greater degree of control" (Madsen, 2008: 1054). Dating rules, like many other parenting techniques, work to "encourage greater conformity in daughters and greater independence in sons" (Kan, McHale, \& Crouter, 2008: 176). The next two women illustrate these differences

"I would always notice a difference in how my mother would raise my brothers and me. When it came to me, she would always tell me to be aware of men and that a lot of them do not care and are usually out for one and one thing only. However, as she said this to me, not once did I hear her tell my brother to not go for girls only to have sex with them, or to be careful with women, never. This contradiction amazed me. How can you tell your daughter to be careful, but then you send out your sons into the world and do not teach them to treat other women as you would want your daughter to be treated."

Another woman had a similar experience with her mother's reactions to her versus her male sibling's dating life. This woman's reaction to the inequality she experiences is not uncommon.

"I could not leave my house after dark like my brothers did. I was to protect my virginity and never have sex until I was married. On the other hand; my mom just gave my brother a bag of condoms and told him if you get a girl pregnant you will marry her. He got to come home as late as he wanted to and did not have to clean or cook for himself. This made me grow up very angry, why was this so unequal? This made me hate being female because I was not able to have the privileges a male could have."

In the following, a young man is confronted with his father's explosive reaction to his sister's romantic life and compares it to his own romantic interests:

"The fact that I had a girlfriend that I could have around my parents had to have been a big deal to my sister because my father would have lost his mind if my sister brought a boy home in high school. I know that my sister dated in high school, but she never felt comfortable with sharing that information with my dad. I remember when my sister was 16, she snuck out of the house one night and the cops brought her home in the middle of the night. My dad was irate! He shouted for hours, he asked who the man was that my sister left the house for, he found out he was a marine so he wanted his rank, his commanding officer, his background, and he probably wanted his head on a chopping block. My sister got in so much trouble for that. My dad unplugged the spark plugs on her car, planted a cactus in front of her window (we lived in the desert), and she was grounded for a long time.

In religious families, parents' disapproval regarding their daughter's romantic life may be even more pronounced due to expectations of chastity and the value of remaining a virgin until marriage. One such struggle between a young woman and her parents is described below:

"Overall, I would consider myself a good daughter, I did well in school, respected both of my parents, and I was a pretty happy child. But when it came to romantic relationships, I did not follow the rules very well. I was not allowed to have a boyfriend in middle school and the majority of high school, but I did it anyway. I kept my teenage boyfriends a secret from my parents because I thought it would be wrong to verbally complain about not being allowed to have a boyfriend. So I called my boyfriends 'just friends'. My father and I have always been really close, when I was with my daddy I didn't feel much infliction of my gender role. I felt that I was 
treated gender neutrally and I enjoyed that. But during my adolescent years, the dynamics of my father and [my] relationship seemed to hit a challenge: boys. This was an area that my dad was protective about and I always preferred to not bring it up because it made me uncomfortable seeing him be so uncomfortable. I liked being seen as wonderful in his eyes and this new topic of boys made things different. [...] Another reason that romantic relationships were a taboo in my household was because of our religious views. I was sent the message that friendships and relationships with the opposite sex were questionable because it opens the possibility of sex. The expectation had been set at about 9 years old that sex was meant to happen during marriage and that my behavior, my way of dressing, the company I kept, the music I listened to, and the thing I did unsupervised could encourage the possibility of fornication. Because this was not only my parent's rule but this was backed by our Christian views and our church community, I felt incredibly conflicted to keep boys away for as long as puberty would allow. One thing that I learned very quickly was that any rules that were backed by Christianity were not be questioned or changed."

\section{The Costs and Effects}

\subsection{Occupational Aspirations and Future Adult Roles}

Fulcher, Sutfinand Patterson (2008) report that-“children's occupational choices were associated with parental division of labor" such that children in households with a traditional division of labor favored gender typical career paths while children from households with more an egalitarian division of labor desired "less stereotyped occupational aspirations than did other children" (338). Another 31-year study of American families showed that the parental division of housework labor, measured when children were one year old, would predict participation in household tasks in their own marriage as adults (Cunningham, 2001). Some of these traditional gendered lessons prove their staying power into adulthood. A woman explains her struggles in her young adult life:

"Being an Armenian woman, I was raised with traditional and cultural beliefs and morals and struggled with what my heart wanted. I absolutely loathed being a woman and had penis envy; I hated that I could not do the same things as my brother, such as dating, going out, speaking my mind, being silly, and other male-approved activities."

\subsection{Breaking the Mold}

Not all families model gender traditional values, nor do all children growing up accept the gendered roles they are expected to engage in. In fact, many parents-consciously or unconsciously, purposely or as a result of circumstance-set egalitarian examples for their children. Stacey and Biblarz (2001) found evidence that children in gay households are more likely to break with stereotypical male-female behavior. In their study, boys raised by lesbians were less aggressive and more nurturing than boys raised in heterosexual families, while daughters of lesbians were likely to become doctors, lawyers, engineers and astronauts, occupations that are traditionally male dominated.

Single parent households also create alternatives to a traditional familial organization. Families with mothers serving as breadwinners offers children a model of a more inclusive view of what women can achieve. Recent research soon to be published by McGinn (2015) has documented that children with a working mother accrue many advantages. In a study of 50,000 adults in 25 countries, daughters of working mothers completed more years of education, were more likely to be employed and in supervisory roles and earned higher incomes. Sons growing up with working mothers contributed more help with childcare and housework.

"While my mom unintentionally taught me there was a difference between being a boy and a girl, she was very intent on teaching me that I should be a very strong woman and that there were no limits to what I could do with my life. She is a single mom and has raised my brother and I on her own from as far back as I can remember. I do not understand how, but she managed to give my brother and me anything and everything we ever wanted. Although she struggled with money and paying bills, my brother and I have never known what it is like to know poverty or to go without food. She sacrificed many of the things she wanted for herself to give my brother and I everything. She is an incredibly strong woman who has managed to give her children everything all on her own and I hope to be the type of woman she is. I hope that if I do one day end up being a single mother that I can handle it with as much grace and pride as she has demonstrated to me. She has shown me that I do not need a man by my side to depend on for the things I want out of my life. I know I am capable of getting eve- 
rything I want on my own because she has done it since I was born. She has fulfilled both the mother and father roles of my life. Men are stereotypically the providers in the household and I grew up with my fulfilling that role. She also holds one of the highest positions at her job and she works hard everyday to ensure that position stays hers."

For better or for worse, these situations are fertile ground for children to grow up with more gender flexible beliefs. In families which stress egalitarianism, children often feel less confined by the limits of typical gendered behavior and may develop unique views about gender roles and identity Rabow (1991).

"My experience with gender was not a negative one. I did not have many influences that attempted to devalue the role of women in my life. My family taught me the importance of being a strong woman, [but also] of being aware of my surroundings for safety reasons. They taught me that education would empower me to do anything that I set my heart to do despite my gender. My church and my family taught me about helping others. I was not only taught this in words but in actions. My mother and my father were passionate about helping others. So my nurturing nature that is said to be gender specific was something that I saw demonstrated by both men and women [...] The teaching I got of my gender role were more often displayed through actions. I understand that socialization of gender roles can limit women [in] particular because we are considered to be inferior. But I believe that my community attempted to prepare me for the gender roles that I would have to wrestle with for the rest of my life. I believe they taught me what women do. They never told me what a woman cannot do and in that I appreciate what I was taught."

In the next story, a father's abuse of his wife leads the young man to reject selected aspects of masculinity

"I was raised to respect women [and] witnessing the battering of my mother has hurt me. It has scared me of my past, and widened the relationship gap between me and my father. After those events, I have grown to denounce forms of male dominance and masculinity. I hated how men acted macho, and how they expressed their masculinity through music, sports, and dating. I distanced myself from many forms of masculinity."

\subsection{Resisting the Mold}

Children can take it upon themselves to break the gender expectations their families set for them, despite the possible repercussions. A young woman describes her rebellious response to her family's discouragement of her involvement in sports,

"As 4th grade came along, I started to play after school sports. My grandfather would get upset at me every time I insisted on playing soccer and basketball. He would say, '...soccer? Why soccer? Those games are for boy; you are not a boy. And well, basketball is okay. Why don't you try playing a girls' sport?' Every time that he would say that to me, I would get upset. I would tell myself, '....well, I can play whatever sport I want. It doesn't matter if I am a girl or a boy. Plus, I am better than the boys.' As my grandfather and my mom would give me a lesson (that I am a girl and girls do not do that), I would want to play those sports more and more just to prove them wrong."

Eagley (1973) has shown even with the reduction of traditional values regarding household organization and division of labor, "women spend approximately twice as much time as men in caring for and helping household members" and "comprise $75 \%$ of the caregivers for older family members and friends" (648). Despite a rise in egalitarian values within many families, women continue to take on more responsibility for the upkeep of the home and raising of the child (Sanchez \& Thompson, 1997). This occurs even when women are the primary financial providers. Household contributions remain highly gendered with women doing 75\% of traditionally feminine domestic duties (cleaning, cooking, and doing laundry) and men doing $70 \%$ of the traditionally masculine tasks (auto repair and yard work) (Greenstein, 2000: 322).

In our final vignette, a young woman describes her future plans for her own non-traditional family.

"As a woman, I am already beginning to feel the pressure of having a family before I turn thirty. People are already asking me when I will be getting married and popping out kids. I have stood my ground on this pretty well stating that I would not be having kids until I have a degree in hand and a proper place to live. I would also like to think I would be married first, but let's be realistic. I feel like as a woman I am constantly being watched [...] Now that I am looking back on all the things I would do as a child, they are definitely adding up to who I am today. They explain [why] I do the things I do now and also offer me a way to prevent the same assimilation [from happening] to my own children. I will not create my daughter to only be nurturing, but also self-reliant. I will teach my son it is okay to dependent on others when he is in need of a helping hand." 


\section{Conclusion}

The voices of these young men and women describing their familial experiences, as well as the research reported, illustrate how family interaction influence gender stereotypes, gender identities, gender relationships, and future gender roles. Strict gender traditional values enforce compliance through punishment of atypical behaviors. Styles of parenting that emphasize gender conformity exact a cost on children and young adults by restricting avenues for self-expression, impacting relationships in later life, and limiting aspirations and career goals. The problems and limitations that arise from encouraging gender role conformity suggest a more holistic approach to child rearing. Children need not be raised to conform to a gender binary. In fact, a healthy gender identity grows from freedom to experiment and defy gendered norms as well as access to a diverse set of male and female role models within the family. When men and women have an "equitable balance in the time and interest with which they participate in work, family and community and when there are personal and institutional measures which reduce the disproportionate men's involvement in work at the expense of meaningful participation in family and community, and women's disproportionate involvement in family at the expense of participation in work and community" (Alice Rossi in Ziegler, 2014) then we shall have men and women appreciating, respecting and loving differences unrelated to stereotypes, traditional roles and exclusively binary genders.

\section{References}

Bandura, A. B., \& Bussey, K. (1999). Social Cognitive Theory of Gender Development and Differentiation. Psychological Review, 106, 676-713.

Carballo, J. J., García-Nieto, R., Álvarez-García, R., Caro-Cañizares, I., López-Castromán, J., Muñoz-Lorenzo, L., de Leon-Martinez, V., \& Baca-García. E. (2013). Sibship Size, Birth Order, Family Structure and Childhood Mental Disorders. Social Psychiatry and Psychiatric Epidemiology, 48, 1327-1333. http://dx.doi.org/10.1007/s00127-013-0661-7

Cowan, G., \& Hoffman, C. D. (1986). Gender Stereotyping in Young Children: Evidence to Support a Concept-Learning Approach. Sex Roles, 14, 211-224.

Cunningham, M. (2001). The Influence of Parental Attitudes and Behaviors on Children's Attitudes Toward Gender and Household Labor in Early Adulthood. Journal of Marriage and Family, 63, 111-122. http://dx.doi.org/10.1111/j.1741-3737.2001.00111.x

Ember, C. R. (1973). Feminine Task Assignment and the Social Behavior of Boys. Ethos, 1, 424-39. http://dx.doi.org/10.1525/eth.1973.1.4.02a00050

Epstein, M., \& Ward, L. M. (2011). Exploring Parent-Adolescent Communication about Gender: Results from Adolescent and Emerging Adult Samples. Sex Roles, 65, 108-18.

Etaugh, C., \& Liss, M. B. (1992). Home, School, and Playroom: Training Grounds for Adult Gender Roles. Sex Roles, 26, 129-147. http://dx.doi.org/10.1007/BF00289754

Fagot, B. I., Leinbach, M. D., \& O’Boyle, C. (1992). Gender Labeling, Gender Stereotyping, and Parenting Behaviors. Developmental Psychology, 28, 225.

Freeman, N. K. (2007). Preschoolers' Perceptions of Gender Appropriate Toys and Their Parents' Beliefs about Genderized Behaviors: Miscommunication, Mixed Messages, or Hidden Truths? Early Childhood Education Journal, 35, $357-366$. http://dx.doi.org/10.1007/s10643-006-0123-x

Fulcher, M., Sutfin, E. L., \& Patterson, C. J. (2008). Individual Differences in Gender Development: Associations with Parental Sexual Orientation, Attitudes, and Division of Labor. Sex Roles, 58, 330-341.

http://dx.doi.org/10.1007/s11199-007-9348-4

Greenstein, T. N. (2000). Economic Dependence, Gender, and the Division of Labor in the Home: A Replication and Extension. Journal of Marriage and Family, 62, 322-335. http://dx.doi.org/10.1111/j.1741-3737.2000.00322.x

Kan, M. L., McHale, S. M., \& Crouter, A. C. (2008). Parental Involvement in Adolescent Romantic Relationships: Patterns and Correlates. Journal of Youth and Adolescence, 37, 168-179. http://dx.doi.org/10.1007/s10964-007-9185-3

Kane, E. W. (2006). "No Way My Boys Are Going to Be Like That!”: Parents' Responses to Children's Gender Nonconformity. Gender \& Society, 20, 149-176. http://dx.doi.org/10.1177/0891243205284276

Kaplan, P. (1991). A Child's Odyssey. St. Paul: West Publishing.

Kniveton, B. H. (1996). An Investigation of Parental Protectiveness of Young Children Traveling to School. British Journal of Sociology of Education, 7, 287-292. http://dx.doi.org/10.1080/0142569860070304

Lauer, R. H., \& Lauer, J. C. (2011). Marriage and Family: The Quest for Intimacy (8th ed). New York: McGraw-Hill Companies. 
Madsen, S. D. (2008). Parents' Management of Adolescents' Romantic Relationships through Dating Rules: Gender Variations and Correlates of Relationship Qualities. Journal of Youth and Adolescence, 37, 1044-1058. http://dx.doi.org/10.1007/s10964-008-9313-8

Marks, J. L., Lam, C. B., \& Mchale, S. M. (2009). Family Patterns of Gender Role Attitudes. Sex Roles, 61, 221-3234. http://dx.doi.org/10.1007/s11199-009-9619-3

Martin, C. L., \& Ruble, D. (2004). Children's Search for Gender Cues Cognitive Perspectives on Gender Development. Current Directions in Psychological Science, 13, 67-70. http://dx.doi.org/10.1111/j.0963-7214.2004.00276.x

McGinn, K. (2015). "It Takes a Family \& Country: Modeling Non-Traditional Gender Roles" with Mayra Ruiz Castro Unpublished International Survey Data. Article by A. Bhattacharya "Kids Are Better off with Working Moms". www.CNN.com

McKee, L., Roland, E., Coffelt, N., Olson, A. L., Forehand, R., Massari, C., Jones, D., Gaffney, C. A., \& Zens, M. S. (2007). Harsh Discipline and Child Problem Behaviors: The Roles of Positive Parenting and Gender. Journal of Family Violence, 22, 187-196. http://dx.doi.org/10.1007/s10896-007-9070-6

Rabow, J. (1991). Rethinking the Father-Son Relationship. Revue Internationale de Sociologie, 2, 60-94. http://dx.doi.org/10.1080/03906701.1991.9971074

Ridgeway, C. L., \& Correll, S. J. (2004). Unpacking the Gender System: A Theoretical Perspective on Gender Beliefs and Social Relations. Gender \& Society, 18, 510-531. http://dx.doi.org/10.1177/0891243204265269

Sanchez, L., \& Thomson, E. (1997). Becoming Mothers and Fathers: Parenthood, Gender, and the Division of Labor. Gender\& Society, 11, 747-772. http://dx.doi.org/10.1177/089124397011006003

Santrock, J. (2013). Childhood Development. 14th Edition, New York: McGraw-Hill Education.

Stacey, J., \& Biblarz, T. J. (2001). How Does the Sexual Orientation of Parents Matter? American Sociological Review, 159-183. http://dx.doi.org/10.2307/2657413

Valentine, G. (1997). "My Son's a Bit Dizzy." "My Wife's a Bit Soft”: Gender, Children and Cultures of Parenting. Gender, Place \& Culture: A Journal of Feminist Geography, 4, 37-62. http://dx.doi.org/10.1080/09663699725495

Weinraub, M., Clemens, L. P., Sockloff, A., Ethridge, T., Gracely, E., \& Myers, B. (1984). The Development of Sex Role Stereotypes in the Third Year: Relationships to Gender Labeling, Gender Identity, Sex-Types Toy Preference, and Family Characteristics. Child Development, 55, 1493-1503. http://dx.doi.org/10.2307/1130019

Ziegler, M. (2014). Abortion and the Constitutional Right (Not) to Procreate. Public Law Research Paper No. 718, University of Richmond Law Review, Vol. 8, pp. 1263, FSU College of Law, Tallahassee, FL: Florida State University. 